\title{
Base metal-catalyzed benzylic oxidation of (aryl)(heteroaryl)methanes with molecular oxygen
}

\author{
Hans Sterckx, Johan De Houwer, Carl Mensch, Wouter Herrebout, \\ Kourosch Abbaspour Tehrani and Bert U. W. Maes*
}

\author{
Full Research Paper \\ Address: \\ Department of Chemistry, University of Antwerp, \\ Groenenborgerlaan 171, B-2020 Antwerp, Belgium \\ Email: \\ Bert U.W. Maes* - bert.maes@uantwerpen.be \\ ${ }^{*}$ Corresponding author \\ Keywords: \\ base metal; benzylic; catalyzed; molecular oxygen; oxygenation
}

\author{
Beilstein J. Org. Chem. 2016, 12, 144-153. \\ doi:10.3762/bjoc. 12.16 \\ Received: 09 October 2015 \\ Accepted: 12 January 2016 \\ Published: 27 January 2016 \\ This article is part of the Thematic Series "Sustainable catalysis". \\ Guest Editor: N. Turner \\ (c) 2016 Sterckx et al; licensee Beilstein-Institut. \\ License and terms: see end of document.
}

Open Access

\begin{abstract}
The methylene group of various substituted 2- and 4-benzylpyridines, benzyldiazines and benzyl(iso)quinolines was successfully oxidized to the corresponding benzylic ketones using a copper or iron catalyst and molecular oxygen as the stoichiometric oxidant. Application of the protocol in API synthesis is exemplified by the alternative synthesis of a precursor to the antimalarial drug Mefloquine. The oxidation method can also be used to prepare metabolites of APIs which is illustrated for the natural product papaverine. ICP-MS analysis of the purified reaction products revealed that the base metal impurity was well below the regulatory limit.
\end{abstract}

\section{Introduction}

Direct oxidation of $\mathrm{C}\left(\mathrm{sp}^{3}\right)-\mathrm{H}$ bonds is a useful and fast method to convert fairly unreactive substrates to useful functional groups for organic synthesis like alcohols, ketones, aldehydes and carboxylic acids. Classical oxidation protocols rely on the use of (super)stoichiometric quantities of oxyanions of toxic metals like $\mathrm{Mn}(\mathrm{VII})$ and $\mathrm{Cr}(\mathrm{VI})[1,2]$. The amount of waste these oxidants produce and limitations on their use by new legislation [3] has prompted scientists to search for more sustainable oxidation methods. The use of transition metal- or organocatalysis in combination with molecular oxygen has received a great deal of attention from the scientific community
[4-7]. Molecular oxygen is considered to be the greenest oxidant available and it is already widely employed by the commodity chemical industry [8]. However, when looking at the preparation of more complex molecules, typical for fine chemicals, the use of aerobic oxidations is more the exception than the norm [9]. This is partly due to the limited synthetic scope and selectivity of the available oxidation methods. Further research into selective and mild aerobic oxidations is therefore of vital importance. Of special interest are the transition metal- and organocatalyzed oxidations of activated methylenes such as in benzylic methylenes or their heteroaromatic an- 
alogues. Due to the activation, the formation of the corresponding ketones and aldehydes becomes feasible under mild conditions. Oxidations of this kind using Oxone ${ }^{\circledR}[10,11], \mathrm{NaOCl}$ [12] or especially peroxides [13-19] as the terminal oxidant are quite numerous. However, transformations using molecular oxygen are rare. Ishii showed that organocatalysts such as $\mathrm{N}$-hydroxyphthalimide (NHPI) in combination with molecular oxygen can be used to perform benzylic oxidations [20]. The aerobic copper-catalyzed $\alpha$-oxygenation of 2 -arylthioacetamides was reported by Moghaddam [21]. In this transformation $\mathrm{CuCl}_{2}$ and $\mathrm{K}_{2} \mathrm{CO}_{3}$ in DMF were used to produce $\alpha$-ketoarylthioacetamides. The coupling of 2 -arylacetaldehydes with anilines resulting in the formation of 2 -aryl- $\alpha$-ketoacetamides was reported by Jiao [22] and a closely related intramolecular variant leading to isatins has been published by Ilangovan [23]. A remarkable $\mathrm{Cu}$-catalyzed chemoselective oxidative $\mathrm{C}-\mathrm{C}$ bond cleavage of methyl ketones was reported by the group of Liu and $\mathrm{Bi}$ [24]. This useful transformation makes use of $\mathrm{CuI} / \mathrm{O}_{2}$ in DMSO to convert methyl ketones into aldehydes in a sustainable manner.

Recently our group reported a synthetic protocol for the copperand iron-catalyzed aerobic oxidation of the methylene group of aryl(di)azinylmethanes using acetic acid as a promotor [25]. The resulting ketones are very valuable as they are intermediates in the synthesis of a variety of pharmaceuticals such as the antimalarial Mefloquine $\left(\operatorname{Lariam}^{\circledR}\right)$, the antihistamine Acrivastine, the $\beta_{2}$-adrenergic agonist Rimiterol and the anxiolytic Bromazepam [26]. Furthermore, they can also be used to synthesize the 1st and 2nd generation antihistamines Carbinoxamine, Bepotastine and Triprolidine through an alternative synthetic route. In addition to these synthetic examples it has been shown by Kamijo that 4-benzoylpyridines can act as efficient organocatalysts in the photoinduced oxidation of secondary alcohols [27]. Very recently the group of Zhuo and Lei disclosed an alteration to our reaction conditions to further extend the substrate scope [28]. Ethyl chloroacetate was used as the promotor instead of acetic acid, allowing the authors to additionally oxidize less reactive alkyl-substituted pyridines. Gao showed that $\mathrm{NH}_{4} \mathrm{I}$ can also be used as an organocatalyst in combination with $\mathrm{AcOH}$ to facilitate the oxidation of benzylpyridines to benzoylpyridines [29]. Satoh and Miura showed that when replacing $\mathrm{O}_{2}$ for $\mathrm{Na}_{2} \mathrm{~S}_{2} \mathrm{O}_{8}$ chemoselective methylenation occurred over oxygenation of the methylene with DMA acting as a one-carbon source [30]. An alternative method to synthesize picolinic amides from picolines and ammonium acetate or amines using a similar oxidation protocol was simultaneously proposed by the groups of Deng and Yin [31,32]. In the current work we study the expansion of the scope of our previously disclosed method and provide specific examples of applications in organic synthesis.

\section{Results and Discussion}

\section{Substrate scope}

In our communication we provided a reaction scope of phenylsubstituted 2-benzylpyridines and showed that both, electronwithdrawing and donating groups are well tolerated. The results additionally indicated that either $\mathrm{Cu}$ and $\mathrm{Fe}$ catalysts $(\mathrm{CuI}$ and $\mathrm{FeCl}_{2} \cdot 4 \mathrm{H}_{2} \mathrm{O}$ ) worked equally well for this substrate class [25]. In the framework of this work a similar study was executed for the regioisomeric 4-benzylpyridines using $\mathrm{FeCl}_{2} \cdot 4 \mathrm{H}_{2} \mathrm{O}$ as the catalyst. Under the standard conditions previously developed for 2-benzylpyridines these substrates smoothly oxidized giving the corresponding ketones in moderate to good yields (Table 1). Also in this case electron-donating as well as electron-withdrawing substituents on the phenyl ring are well tolerated and their electronic properties have little influence on the yield of the reaction. Even substituents that are sensitive to oxidation such as $\mathrm{NH}_{2}(\mathbf{2 b})$ and SMe (2c) appear to be no problem although the reaction products were isolated in slightly lower yields.

Table 1: Iron-catalyzed aerobic oxidation of phenyl-substituted
4-benzylpyridines (1) ${ }^{a}$

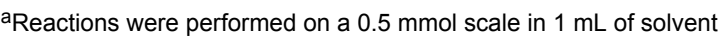
using 1 atmosphere of $\mathrm{O}_{2}$ (balloon). ${ }^{b}$ Isolated yields.

Next, pyridine rather than phenyl-substitution was studied. In contrast to the phenyl-substituted compounds, substitution on the pyridine ring exerted a large influence on the rate of the reaction (Table 2). This is not surprising when considering the mechanism of the reaction involving an initial acid catalyzed imine-enamine tautomerization (the calculation of the equilibrium constants can be found in Supporting Information File 1, 
Table 2: Iron and copper-catalyzed aerobic oxidation of pyridine-substituted 2-benzylpyridines (3). ${ }^{\text {a }}$

\begin{tabular}{|c|c|c|c|c|c|c|}
\hline \multirow[b]{2}{*}{ Entry } & \multicolumn{2}{|c|}{$3 a-i$} & \multicolumn{2}{|c|}{$\begin{array}{c}\begin{array}{c}\text { catalyst }(10 \text { mol \%) } \\
\text { AcOH (1-3 equiv) }\end{array} \\
\underset{\mathrm{O}_{2}}{\mathrm{DMSO}} \\
24 \mathrm{~h}, 100-130^{\circ} \mathrm{C}\end{array}$} & $-\mathbf{i}$ & \multirow[b]{2}{*}{ Yield $4(\%)^{b}$} \\
\hline & Catalyst & Substrate & $\mathrm{R}$ & Product & Yield $\mathbf{3}(\%)^{\mathrm{b}}$ & \\
\hline 1 & $\mathrm{FeCl}_{2} \cdot 4 \mathrm{H}_{2} \mathrm{O}$ & $3 a$ & $5-\mathrm{CN}$ & $4 a$ & 19 & 67 \\
\hline 2 & Cul & $3 a$ & $5-\mathrm{CN}$ & $4 a$ & 18 & 66 \\
\hline 3 & Cul & $3 a$ & $5-\mathrm{CN}^{\mathrm{C}}$ & $4 a$ & 0 & 83 \\
\hline 4 & $\mathrm{FeCl}_{2} \cdot 4 \mathrm{H}_{2} \mathrm{O}$ & $3 b$ & 5-Me & $4 b$ & 9 & 73 \\
\hline 5 & Cul & $3 b$ & $5-\mathrm{Me}$ & $4 b$ & 9 & 82 \\
\hline 6 & Cul & $3 b$ & $5-\mathrm{Me}^{\mathrm{C}}$ & $4 b$ & 0 & 72 \\
\hline 7 & $\mathrm{FeCl}_{2} \cdot 4 \mathrm{H}_{2} \mathrm{O}$ & $3 c$ & 5-OMe & 4c & 65 & 15 \\
\hline 8 & Cul & $3 c$ & 5-OMe & 4c & 66 & 15 \\
\hline 9 & Cul & $3 c$ & $5-O M e^{d, e}$ & 4c & 0 & 65 \\
\hline 10 & $\mathrm{FeCl}_{2} \cdot 4 \mathrm{H}_{2} \mathrm{O}$ & $3 d$ & $5-\mathrm{CO}_{2} \mathrm{Me}$ & $4 d$ & 0 & 69 \\
\hline 11 & Cul & $3 d$ & $5-\mathrm{CO}_{2} \mathrm{Me}$ & $4 d$ & 0 & 62 \\
\hline 12 & $\mathrm{FeCl}_{2} \cdot 4 \mathrm{H}_{2} \mathrm{O}$ & $3 e$ & 5-NHCOMe & $4 e$ & 0 & 64 \\
\hline 13 & Cul & $3 e$ & 5-NHCOMe & $4 e$ & 27 & 56 \\
\hline 14 & Cul & $3 e$ & $5-\mathrm{NHCOMe}^{\mathrm{C}}$ & $4 e$ & 0 & 91 \\
\hline 15 & $\mathrm{FeCl}_{2} \cdot 4 \mathrm{H}_{2} \mathrm{O}$ & $3 f$ & $4-\mathrm{Cl}$ & $4 f$ & 0 & 85 \\
\hline 16 & Cul & $3 f$ & $4-\mathrm{Cl}$ & $4 f$ & 8 & 88 \\
\hline 17 & $\mathrm{FeCl}_{2} \cdot 4 \mathrm{H}_{2} \mathrm{O}$ & $3 g$ & $3-\mathrm{Cl}$ & $\mathbf{4 g}$ & 73 & 23 \\
\hline 18 & Cul & $3 g$ & $3-\mathrm{Cl}$ & $4 \mathrm{~g}$ & 71 & 22 \\
\hline 19 & Cul & $3 g$ & $3-C^{d, e}$ & $4 \mathrm{~g}$ & 0 & 87 \\
\hline 20 & $\mathrm{FeCl}_{2} \cdot 4 \mathrm{H}_{2} \mathrm{O}$ & $3 \mathrm{~h}$ & $5-\mathrm{Cl}$ & $4 h$ & 70 & 20 \\
\hline 21 & Cul & $3 h$ & $5-\mathrm{Cl}$ & $4 \mathrm{~h}$ & 69 & 15 \\
\hline 22 & Cul & $3 h$ & $5-C^{d, e}$ & $4 \mathrm{~h}$ & 0 & 92 \\
\hline 23 & $\mathrm{FeCl}_{2} \cdot 4 \mathrm{H}_{2} \mathrm{O}$ & $3 \mathbf{i}$ & $6-\mathrm{Cl}$ & $4 i$ & 90 & 0 \\
\hline 24 & Cul & $3 \mathbf{i}$ & $6-\mathrm{Cl}$ & $4 i$ & 91 & 0 \\
\hline 25 & Cul & $3 \mathbf{i}$ & $6-\left.\mathrm{Cl}\right|^{e, f}$ & $4 i$ & 0 & 59 \\
\hline
\end{tabular}

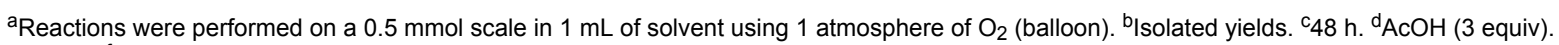
e $130{ }^{\circ} \mathrm{C}$. ${ }^{\text {TFA }}$ (3 equiv)

Table S1) [33]. As the substituent is now located in the ring where the tautomerization will take place the electronic effect and the position of this substituent is expected to have a large effect on it. In general one expects the tautomerization to proceed more efficiently when the pyridine nitrogen becomes more basic and the methylene hydrogen becomes more acidic. In Table 2 the results on pyridine-substituted 2-benzylpyridines using both $\mathrm{Fe}$ and $\mathrm{Cu}$ catalysis are shown. Under the standard conditions only a small number of substrates reached full conversion after 24 hours. Based on our findings that placing substituents on the phenyl ring, both in 2- and 4-benzylpyridines and irrespective of their electronic nature, has little influence on the yield of the reaction the largest substituent effect is expected to be on the basicity of the pyridine nitrogen and not that much on the acidity of the methylene hydrogen.
While the thermodynamical equilibrium constant between the imine and enamine tautomers predicts whether or not a substrate can be oxidized (see Supporting Information File 1), it does not provide an explanation for the incomplete conversion that is seen in most cases of the pyridine-substituted 2-benzylpyridines. We attribute the low conversions to the fact that the pyridine nitrogen becomes less basic and therefore protonation by $\mathrm{AcOH}$ becomes unfavored. This is supported by the fact that the rate of deuterium incorporation in the benzylic position of $\mathbf{1 6}$ and $\mathbf{3 h}$ through acid-catalyzed imine-enamine tautomerization is dependent on the strength of the acid used (Figure 1). The rate of deuterium incorporation in 2-benzylpyridine (16, $\left.\mathrm{p} K_{\mathrm{a}} \approx 5.2\right)$ is much faster when using TFA- $d_{1}$ than with AcOH$d_{4}$ [34,35]. With the less basic 2-benzyl-5-chloropyridine (3h, $\mathrm{p} K_{\mathrm{a}} \approx 3.0$ ) the difference is even more pronounced: Almost no 

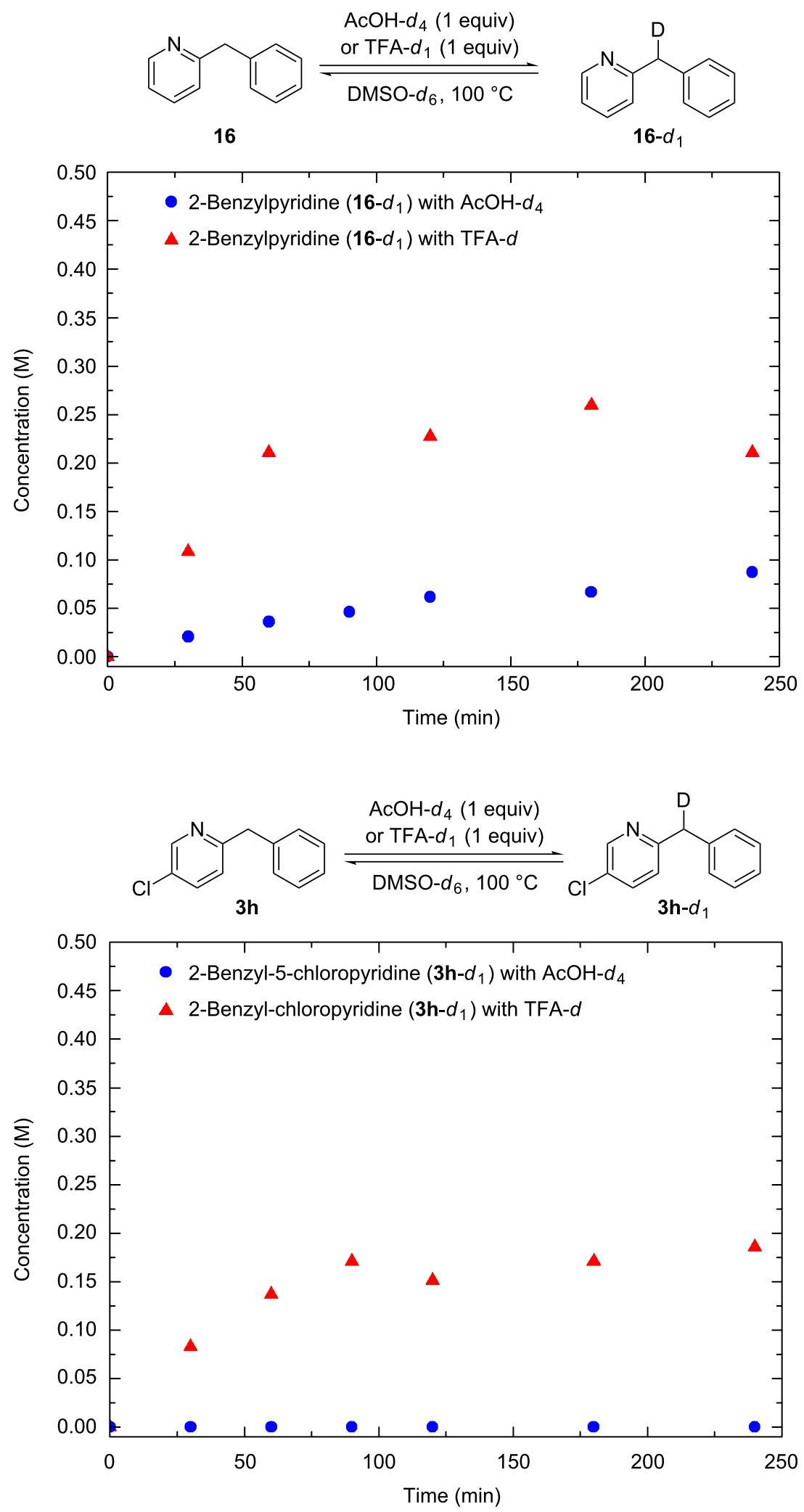

Figure 1: Hydrogen-deuterium exchange through acid-catalyzed imine-enamine tautomerization of $3 \mathrm{~h}(0.5 \mathrm{M})$ and $16(0.5 \mathrm{M})$ using AcOH- $d_{4}(0.5 \mathrm{M})$ or TFA-d ${ }_{1}(0.5 \mathrm{M}) .{ }^{1} \mathrm{H}$ NMR spectroscopy was used to quantify the monodeuterated species. 
deuterium incorporation could be detected using AcOH- $d_{4}$ while the reaction ran smoothly using the stronger acid TFA- $d_{1}$. From this we conclude that when the pyridine nitrogen becomes less basic and protonation by the acid thus becomes more difficult, using more equivalents of the acid or a stronger acid is needed to reach full conversion. When we compare the different $\mathrm{p} K_{\mathrm{a}}$ values of substituted pyridines we see that 2-benzylpyridine $\left(\mathbf{1 6}, \mathrm{p} K_{\mathrm{a}} \approx 5.2\right)$ is one of the most basic pyridines $[34,35]$. Substituents in the 5-position generally give poor conversion in accordance with their lower $\mathrm{p} K$ a values: 5-CN ( $\mathrm{p} K_{\mathrm{a}} \approx 1.3$, Table 2, entries 1 and 2 ), 5-OMe ( $\mathrm{p} K_{\mathrm{a}} \approx 4.9$, Table 2, entries 7 and 8$)$ and $5-\mathrm{Cl}\left(\mathrm{p} K_{\mathrm{a}} \approx 3.0\right.$, Table 2, entries 20 and 21) with the exception of $5-\mathrm{CO}_{2} \mathrm{Me}\left(\mathrm{p} K_{\mathrm{a}} \approx 3.1\right.$, Table 2, entries 10 and 11). When investigating regioisomeric substrates featuring chloro substituents in all possible positions of the pyridine ring only the $4-\mathrm{Cl}\left(\mathrm{p} K_{\mathrm{a}} \approx 3.8\right.$, Table 2 , entries 15 and 16) substrate reaches full conversion under the standard conditions. The 3- $\mathrm{Cl}$ and 5-Cl regioisomers have a similar $\mathrm{p} K_{\mathrm{a}}$ value $\left(\mathrm{p} K_{\mathrm{a}} \approx 2.98\right)$ and therefore show similar reactivity (Table 2, entries 17 and 18 and entries 20 and 21) with only limited conversion. A remarkable case is the 6-Cl-substituted substrate ( $\mathrm{p} K_{\mathrm{a}} \approx 0.8$, Table 2, entries 23 and 24 ), which did not react at all under the standard conditions. The low basicity of the pyridine nitrogen is the reason for this lack of reactivity. In addition the enamine form of this compound is also highly unfavored (see Supporting Information File 1).

To reach full conversion for all substrates we re-optimized the reaction conditions. Although similar results for $\mathrm{Fe}$ and $\mathrm{Cu}$ catalysis were obtained after $24 \mathrm{~h}, \mathrm{CuI}$ was selected for this purpose. The reasoning behind this is reflected in the chemoselectivity experiments (vide infra), where it was shown that $\mathrm{CuI}$ is a slightly more potent catalyst than $\mathrm{FeCl}_{2} \cdot 4 \mathrm{H}_{2} \mathrm{O}$. Additionally, comparison of the reaction rate for both catalysts on the standard substrate 2-benzylpyridine (16) further supports this $\left(\mathrm{v}_{\mathrm{i}, \mathrm{Cu}}=1.088 \times 10^{-3} \mathrm{M} \mathrm{min}^{-1} ; \mathrm{v}_{\mathrm{i}, \mathrm{Fe}}=1.013 \times 10^{-3} \mathrm{M} \mathrm{min}^{-1}\right.$, see Supporting Information File 1, Figure S2). For substrates that already gave reasonable conversions $(>60 \%)$ using the standard conditions (Table 2, entries 3, 6 and 14) the reaction time was doubled to 48 hours which was sufficient to achieve full conversion. For substrates that are harder to oxidize $(<60 \%$ conversion) due to too low $\mathrm{p} K_{\mathrm{a}}$ a combination of a higher temperature and the addition of more (three) equivalents of acetic acid was needed (Table 2, entries 9, 19 and 22). Considering the low basicity of compound $\mathbf{3 i}, 3$ equivalents of the stronger acid TFA were used (Table 2, entry 25).

Next, the effect of benzoannulation (quinoline) and $\mathrm{C}-\mathrm{H}$ for $\mathrm{N}$ substitution (diazines) in the pyridine ring was studied. Scheme 1 provides an overview of the results for these more challenging substrates. Interestingly, phenyl(quinolin-2yl)methanone (6a) and phenyl(quinolin-4-yl)methanone (6b) were formed in moderate yields indicating that larger aromatic systems are compatible with the reaction conditions. In the case of 2-(4-chlorobenzyl)pyrimidine (5c) the standard conditions allowed smooth oxidation providing the target compound in an excellent yield. For the regioisomeric diazine, (4-chlorobenzyl)pyrazine (5d), no oxidation was observed after $24 \mathrm{~h}$ at $100{ }^{\circ} \mathrm{C}$. To our delight, by increasing the reaction temperature to $130{ }^{\circ} \mathrm{C}$, (4-chlorophenyl)(pyrazin-2-yl)methanone (6d) could

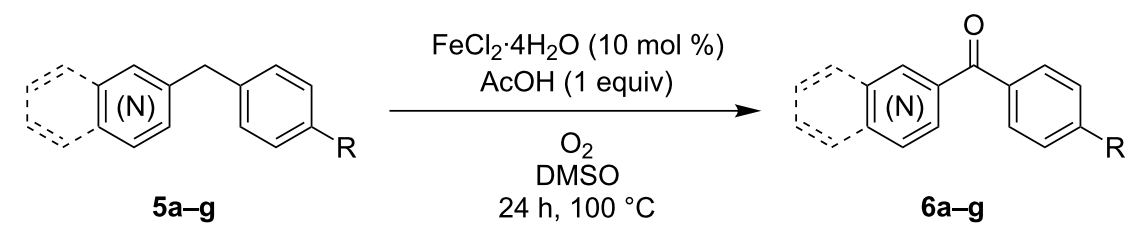<smiles>O=C(c1ccccc1)c1ccc2ccccc2n1</smiles><smiles>O=C(c1ccc(Cl)cc1)c1ccncn1</smiles>

6 e

$0 \%\left(130^{\circ} \mathrm{C}\right)$<smiles>O=C(c1ccccc1)c1ccnc2ccccc12</smiles>

6b<smiles>O=C(c1ccc(Cl)cc1)c1ncccn1</smiles>

$6 \mathrm{c}$

$90 \%$<smiles>O=C(c1ccc(Cl)cc1)c1cnccn1</smiles>

6d $92 \%\left(130{ }^{\circ} \mathrm{C}\right)$<smiles>Cc1nccc(C(=O)c2ccccc2)n1</smiles><smiles>Cc1ccc(C(=O)c2ccccc2)nn1</smiles>

$6 \mathrm{~g}$

$81 \%$ 
be obtained in $92 \%$ yield. In contrast to the two former cases, 4-(4-chlorobenzyl)pyrimidine (5e) could neither be oxidized at $100{ }^{\circ} \mathrm{C}$ nor at $130^{\circ} \mathrm{C}$. Competitive $\mathrm{C}-\mathrm{H}$ activation of the 2 position is presumed to be the reason for this observation. Blocking this position by a methyl group (5f) delivered the corresponding ketone $\mathbf{6 f}$, albeit in a poor yield of $40 \%$, thus supporting the metalation hypothesis. The regioisomer of diazine 5f, 3-benzyl6-methylpyridazine $(\mathbf{5 g})$, could be smoothly oxidized to the corresponding ketone in $81 \%$ yield. It is worth mentioning that in 5f as well as $\mathbf{5 g}$ no additional oxidation of the methyl group was seen [25].

\section{Applications}

An example of an important pharmaceutical which is industrially prepared from an azinyl benzoazinyl ketone, namely $(2,8$ bis(trifluoromethyl)quinolin-4-yl)(pyridin-2-yl)methanone (10), is the antimalarial Mefloquine (13) [36]. This drug is listed on the World Health Organization essential medicines list and despite numerous side effects it remains one of the most effective antimalarial drugs on the market [37,38]. Its classical synthesis (Scheme 2, top) is based on the lithiation of 4-bromo-2,8bis(trifluoromethyl)quinoline (7a) and quenching with $\mathrm{CO}_{2}$ resulting in the formation of 2,8-bis(trifluoromethyl)quinoline-4carboxylic acid (8). Reaction of $\mathbf{8}$ with in situ generated 2-pyridyllithium (9) finally yields ketone 10 [39].

We considered a new approach based on 4-(pyridin-2ylmethyl)-2,8-bis(trifluoromethyl)quinoline (12) as the sub- strate. This compound is structurally interesting as it is activated by both a pyridin-2-yl and a quinolin-4-yl moiety (Scheme 2, bottom). The synthesis of substrate 12 was accomplished by a cross-coupling reaction of pyridine alcohol 11 with commercial 4-chloro-2,8-bis(trifluoromethyl)quinoline (7b) according to a procedure published by Oshima [40]. In this way, 12 was obtained in $63 \%$ yield and its subsequent Fe-catalyzed oxidation provided $\mathbf{1 0}$ in $63 \%$ isolated yield. In principle substrate $7 \mathbf{a}$ could also be used but the chloro analogue is cheaper. The final reduction of $\mathbf{1 0}$ into Mefloquine has been described earlier and can also be achieved in an enantioselective manner [41].

Human metabolism can produce metabolites of pharmaceuticals that possess completely different properties such as for instance biological activity, toxicity and clearance rates. Rapid identification and synthesis of potential drug metabolites is therefore of great importance to facilitate the drug discovery process [42]. For this purpose chemoselective oxidation protocols are a valuable tool since they can provide us with metabolites typically generated by cytochrome P450 enzymes. Bearing this in mind we attempted to oxygenate the benzylic position of the antispasmodic drug papaverine (14) applying our oxidation protocol (Scheme 3). The resulting compound is known as papaveraldine (15), a byproduct from the extraction of papaverine from Papaver somniferum. Papaverine is a challenging substrate as besides the methylene part it also features two oxidation sensitive veratrole units. Interestingly, a highly chemose-

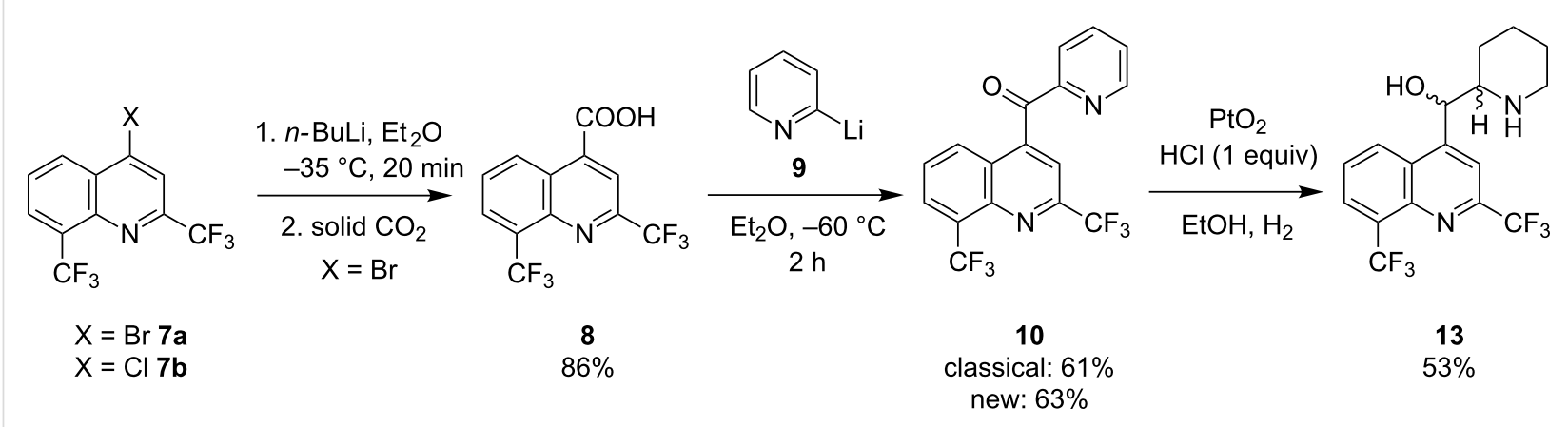

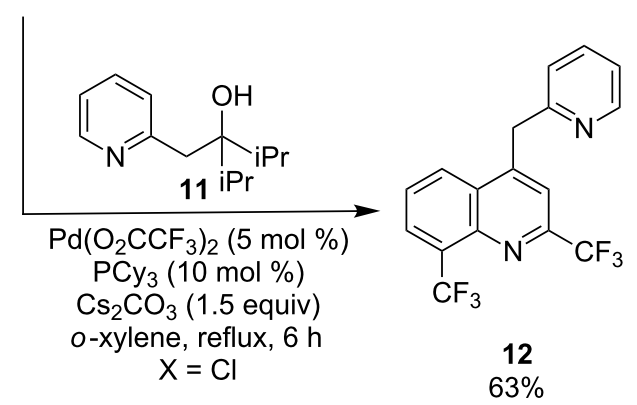

$\mathrm{FeCl}_{2} \cdot 4 \mathrm{H}_{2} \mathrm{O}(10 \mathrm{~mol} \%)$ $\mathrm{AcOH}$ (1 equiv) 


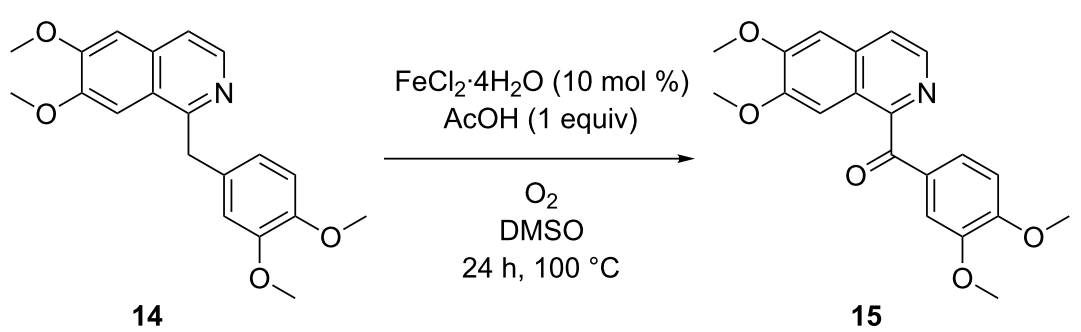

$60 \%$

Scheme 3: Iron-catalyzed aerobic oxidation of papaverine (15).

lective oxidation was observed and compound $\mathbf{1 5}$ was isolated in $60 \%$ yield.

\section{Trace metal analysis}

When using transition metal catalysis in the synthesis of compounds designated for application (pharmaceuticals, agrochemicals, materials) it is of vital importance to control and determine any metal impurity in the reaction product. In case the selected purification methods proved insufficient to get the metal contaminations below the maximum allowed threshold value set for active ingredients (AIs), an extra treatment might be required. This is especially true if the catalysis is performed in a late stage of a synthesis thus making the method less attractive and sustainable. While class 1 metals such as $\mathrm{Pd}$ and $\mathrm{Pt}$ have oral exposure limits of $10 \mathrm{ppm}, \mathrm{Cu}$ and $\mathrm{Fe}$ are respectively class 2 and class 3 metals with oral exposure limits of $250 \mathrm{ppm}$ and $1300 \mathrm{ppm}$ [43]. The fact that $\mathrm{Cu}$ and $\mathrm{Fe}$ are more abundant, cheaper and benign makes them an interesting choice as transition metal catalysts. To determine the $\mathrm{Cu}$ and $\mathrm{Fe}$ contents present in our samples ICP-MS analysis was performed. Copper contents ranged from 5 to $21 \mathrm{ppm}$, all well below the limit of $250 \mathrm{ppm}$. Iron contents were slightly higher ranging from 29 to $57 \mathrm{ppm}$ but again still well below the regulatory maximum value (see Supporting Information File 1, Figure $\mathrm{S} 1)$. It should be noted that these values pertain to the purified compounds after column chromatography. The influence of the work-up procedure on the remaining metal impurities was investigated for one of our applications, namely the papaveraldine (15) synthesis (Table 3). Applying the standard purifica- tion resulted in $54 \mathrm{ppm}$ of Fe remaining. Omitting the column chromatography step and solely performing the aqueous extraction provided a much higher value, namely $1097 \mathrm{ppm}$. However, if after the extraction a recrystallization step of the reaction product is performed the Fe level can be lowered further to $300 \mathrm{ppm}$ which is well below the legal limit for oral exposure (see Supporting Information File 1).

\section{Alternative solvents}

A solvent screening was subsequently performed focusing mainly on greener solvents than DMSO with a boiling point above $100{ }^{\circ} \mathrm{C}$ in order to allow a direct comparison at the same reaction temperature $[44,45]$ (Table 4 ). All reactions were performed in a round-bottomed flask equipped with a reflux condenser under oxygen atmosphere at a $5 \mathrm{mmol}$ scale to be able to reliably quantify remaining starting material. 2-Benzylpyridine (16) was selected as the substrate for this study. The reaction in anisole and $n$-BuOAc gave full conversion after 24 hours with excellent yields. With 1,4-dioxane, toluene, cyclopentyl methyl ether and $n$ - $\mathrm{BuOH}$ as the solvent some starting product was recovered, however, with a good mass balance suggesting that the reaction is just slower in these solvents than in DMSO. From this we can conclude that the reaction is compatible with a variety of other solvents. In addition to the above results, Kappe et al. successfully applied our protocol in a flow process [46]. They intensified the process by working at $200{ }^{\circ} \mathrm{C}$ which allowed them to lower the catalyst loading $\left(\mathrm{FeCl}_{3}\right)$ to $5 \mathrm{~mol} \%$ and to omit acetic acid as the activator. As DMSO degraded and produced repulsive odors at these high

Table 3: The influence of the purification method on the amount of Fe impurities in papaveraldine (15) after oxidation.

\begin{tabular}{lll} 
Entry & Purification method & Fe impurity in 15 (ppm) \\
\hline 1 & Extraction $^{\mathrm{a}}+$ column chromatography $^{\mathrm{b}}$ & 54 \\
2 & Extraction $^{\mathrm{a}}$ & 1097 \\
3 & Extraction $^{\mathrm{a}}+$ recrystallization $^{\mathrm{c}}$ & 300 \\
\hline
\end{tabular}

${ }^{a}$ Washing subsequently with sat. aq $\mathrm{NaHCO}_{3}$ and brine, extraction with dichloromethane. ${ }^{\text {b }}$ Silica flash cartridge applying a heptane/ethyl acetate gradient. 'Recrystallization from a $2 \mathrm{M} \mathrm{HCl}$ solution. 
temperatures the authors switched to propylene carbonate as the solvent.

Table 4: An extended solvent screening for the base metal-catalyzed aerobic oxidation reaction. ${ }^{\text {a }}$

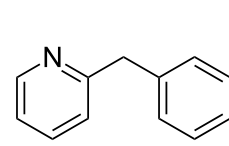

16

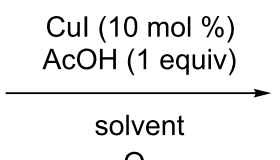

$\mathrm{O}_{2}$

$100^{\circ} \mathrm{C}, 24 \mathrm{~h}$

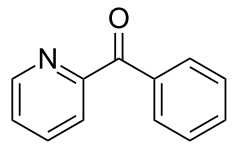

17

\begin{tabular}{|c|c|c|c|}
\hline Entry & Solvent $^{b}$ & Yield $16(\%)^{c}$ & Yield $17(\%)^{c}$ \\
\hline 1 & DMSO $^{d}$ & 0 & 87 \\
\hline 2 & anisole $e^{e}$ & 0 & 85 \\
\hline 3 & $n-\mathrm{BuOAc}^{\mathrm{e}}$ & 0 & 89 \\
\hline 4 & 1,4-dioxane ${ }^{f}$ & 2 & 85 \\
\hline 5 & toluene ${ }^{d}$ & 18 & 67 \\
\hline 6 & CPME $^{d}$ & 5 & 80 \\
\hline 7 & $n-\mathrm{BuOH}^{\mathrm{e}}$ & 5 & 73 \\
\hline
\end{tabular}

aReactions were performed on a $5 \mathrm{mmol}$ scale in $10 \mathrm{~mL}$ of solvent using 1 atmosphere of $\mathrm{O}_{2}$ (balloon). ${ }^{b}$ Classification of solvents as provided in [44]. CIsolated yields. ${ }^{\mathrm{d}}$ Problematic. ${ }^{\mathrm{e}}$ Recommended. fHazardous.

\section{Chemoselectivity}

When multiple activated methylene motifs are present the chemoselective oxidation of one of these positions can be achieved as we previously exemplified for 2-methyl-6-(4methylbenzyl)pyridine (18b, Table 5, entries 4 and 5). This interesting selectivity was further expanded on 6-(4-methyl- benzyl)-2-methylpyrazine (18a). Pyrazine 18a features three possible positions for methylene oxidation: a benzyl, benzhydryl and a 1,4-diazinylmethyl moiety. When 18a was submitted to the $\mathrm{Cu}$-catalyzed reaction conditions at $130{ }^{\circ} \mathrm{C}$, only the bis-oxidation product 6-(4-methylbenzoyl)pyrazine-2carbaldehyde (20a) was obtained in $61 \%$ (Table 5, entry 1 ). Interestingly, when switching to $\mathrm{FeCl}_{2} \cdot 4 \mathrm{H}_{2} \mathrm{O}$ as the catalyst in the reaction, only mono-oxidation at the benzhydrylic methylene occurred, providing (6-methylpyrazin-2-yl)( $p$ tolyl)methanone (19a) in 57\% yield (Table 5, entry 2). A similar chemoselectivity was observed for the oxidation of $\mathbf{1 8 b}$ where $\mathrm{Cu}$ catalysis lead to bis-oxidation (20b, Table 5, entry 4$)$ while Fe catalysis resulted in mono-oxidation $(\mathbf{1 9 b}$, Table 5, entry 5).

When the reaction with $\mathbf{1 8 a}$ using $\mathrm{Cu}$ catalysis is performed in $n$-BuOAc as solvent instead of DMSO only compound 19a was isolated after 48 hours of reaction (starting material was still present after 24 hours, Table 5, entry 3 ). The same trend was observed in the reaction of $\mathbf{1 8 b}$. Here under $\mathrm{Cu}$ catalysis at $130{ }^{\circ} \mathrm{C}$ in $n$-BuOAc also only benzhydrylic oxidation occurred and (6-methylpyridin-2-yl)(p-tolyl)methanone (19b) was isolated in $64 \%$ yield as the sole product. These results demonstrate that the oxidation power of the catalytic system can be tuned by careful selection of the solvent as well as the base metal.

\section{Conclusion}

This work shows that the oxidation protocol disclosed in 2012 by our group can be applied to a much broader substrate scope than originally investigated. Furthermore we have shown that when the nature of the substituents does not permit full conver-

Table 5: Chemoselectivity obtained by selection of catalyst and solvent. ${ }^{a}$

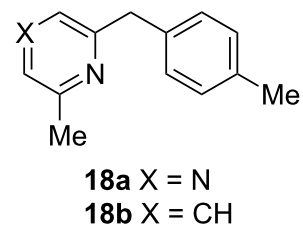

$18 b X=\mathrm{CH}$

\begin{tabular}{llllll}
\hline Entry & Substrate & Catalyst & Solvent & Yield $\mathbf{1 9}(\%)^{\mathrm{b}}$ & Yield 20 (\%) \\
\hline 1 & $\mathbf{1 8 a}$ & $\mathrm{Cul}$ & DMSO & 0 & 61 \\
2 & $\mathbf{1 8 a}$ & $\mathrm{FeCl} 2 \cdot 4 \mathrm{H}_{2} \mathrm{O}$ & DMSO & 57 & 0 \\
3 & $\mathbf{1 8 a}$ & $\mathrm{Cul}$ & $n$-BuOAc & $78^{\mathrm{c}}$ & 0 \\
4 & $\mathbf{1 8 b}^{\mathrm{d}}$ & $\mathrm{Cul}$ & DMSO & 0 & 62 \\
5 & $\mathbf{1 8 b}^{\mathrm{d}}$ & $\mathrm{FeCl}_{2} \cdot 4 \mathrm{H}_{2} \mathrm{O}$ & DMSO & 85 & 0 \\
6 & $\mathbf{1 8 b}$ & $\mathrm{Cul}$ & $n$-BuOAc & 64 & 0 \\
\hline
\end{tabular}

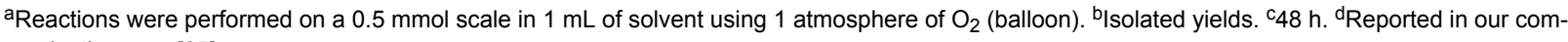
munication, see [25]. 
sion after 24 hours, the standard conditions can be easily amended to increase the rate of the reaction. ICP-MS analysis was performed on a representative set of molecules from the scope disclosed to determine the $\mathrm{Cu}$ or $\mathrm{Fe}$ impurities remaining after work-up of the reaction products. This revealed that only low amounts remained, that are well below the regulatory limits. In addition, for papaveraldine a comparison between different purification procedures was performed in order to determine their influence on the amount of metal impurity remaining. While the reaction is compatible with a large number of solvents including sustainable ones, DMSO appears to give the fastest reactions. This is also reflected in the chemoselectivity studies where DMSO is the only solvent in which oxidation of a (di)azinylmethyl is possible.

\section{Supporting Information}

\section{Supporting Information File 1}

Experimental procedures, compound characterization data and copies of ${ }^{1} \mathrm{H}$ and ${ }^{13} \mathrm{C}$ NMR spectra of all new starting materials and reaction products.

[http://www.beilstein-journals.org/bjoc/content/ supplementary/1860-5397-12-16-S1.pdf]

\section{Acknowledgements}

This work was supported by the Research Foundation Flanders (FWO-Flanders), the Agency for Innovation by Science and Technology (IWT-Flanders), the University of Antwerp (BOF, IOF) and the Hercules Foundation. The authors thank Philippe Franck, Heidi Seykens and Norbert Hancke for technical assistance.

\section{References}

1. Shaabani, A.; Mirzaei, P.; Naderi, S.; Lee, D. G. Tetrahedron 2004, 60, 11415-11420. doi:10.1016/j.tet.2004.09.087

2. Rathore, R.; Saxena, N.; Chandrasekaran, S. Synth. Commun. 1986, 16, 1493-1498. doi:10.1080/00397918608056400

3. European chemicals agency (ECHA) website. http://echa.europa.eu/web/guest/regulations/reach/legislation.

4. Sun, C.-L.; Li, B.-J.; Shi, Z.-J. Chem. Rev. 2011, 111, 1293-1314. doi:10.1021/cr100198w

5. Allen, S. E.; Walvoord, R. R.; Padilla-Salinas, R.; Kozlowski, M. C. Chem. Rev. 2013, 113, 6234-6458. doi:10.1021/cr300527g

6. Shi, Z.; Zhang, C.; Tang, C.; Jiao, N. Chem. Soc. Rev. 2012, 41, 3381-3430. doi:10.1039/c2cs15224j

7. Punniyamurthy, T.; Velusamy, S.; Iqbal, J. Chem. Rev. 2005, 105, 2329-2364. doi:10.1021/cr050523v

8. Campbell, A. N.; Stahl, S. S. Acc. Chem. Res. 2012, 45, 851-863. doi:10.1021/ar2002045

9. Caron, S.; Dugger, R. W.; Ruggeri, S. G.; Ragan, J. A.; Ripin, D. H. B. Chem. Rev. 2006, 106, 2943-2989. doi:10.1021/cr040679f
10. Ojha, L. R.; Kudugunti, S.; Maddukuri, P. P.; Kommareddy, A.; Gunna, M. R.; Dokuparthi, P.; Gottam, H. B.; Botha, K. K.; Parapati, D. R.; Vinod, T. K. Synlett 2009, 1, 117-121. doi:10.1055/s-0028-1087384

11. Moriyama, K.; Takemura, M.; Togo, H. Org. Lett. 2012, 14, 2414-2417. doi:10.1021/ol300853z

12. Jin, C.; Zhang, L.; Su, W. K. Synlett 2011, 10, 1435-1438. doi:10.1055/s-0030-1260760

13. Pan, J.-F.; Chen, K.-M. J. Mol. Catal. A: Chem. 2001, 176, 19-22. doi:10.1016/S1381-1169(01)00238-2

14. Velusamy, S.; Punniyamurthy, T. Tetrahedron Lett. 2003, 44, 8955-8957. doi:10.1016/j.tetlet.2003.10.016

15. Bonvin, Y.; Callens, E.; Larrosa, I.; Henderson, D. A.; Oldham, J.; Burton, A. J.; Barrett, A. G. M. Org. Lett. 2005, 7, 4549-4552. doi:10.1021/ol051765k

16. Catino, A. J.; Nichols, J. M.; Choi, H.; Gottipamula, S.; Doyle, M. P. Org. Lett. 2005, 7, 5167-5170. doi:10.1021/ol0520020

17. Pavan, C.; Legros, J.; Bolm, C. Adv. Synth. Catal. 2005, 347, 703-705. doi:10.1002/adsc.200404315

18. Nakanishi, M.; Bolm, C. Adv. Synth. Catal. 2007, 349, 861-864. doi:10.1002/adsc.200600553

19. Zhang, J. T.; Wang, Z. T.; Wang, Y.; Wan, C. F.; Zheng, X. Q.; Wang, Z. Y. Green Chem. 2009, 11, 1973-1978. doi:10.1039/b919346b

20. Ishii, Y.; Nakayama, K.; Takeno, M.; Sakaguchi, S.; Iwahama, T.; Nishiyama, Y. J. Org. Chem. 1995, 60, 3934-3935. doi:10.1021/jo00118a002

21. Moghaddam, F. M.; Mirjafary, Z.; Saeidian, H.; Javan, M. J. Synlett 2008, 6, 892-896. doi:10.1055/s-2008-1042925

22. Zhang, C.; Xu, Z.; Zhang, L.; Jiao, N. Angew. Chem., Int. Ed. 2011, 50, 11088-11092. doi:10.1002/anie.201105285

23. llangovan, A.; Satish, G. Org. Lett. 2013, 15, 5726-5729. doi:10.1021/ol402750r

24.Zhang, L.; Bi, X.; Guan, X.; Li, X.; Liu, Q.; Barry, B.-D.; Liao, P. Angew. Chem., Int. Ed. 2013, 52, 11303-11307. doi:10.1002/anie.201305010

25. De Houwer, J.; Abbaspour Tehrani, K.; Maes, B. U. W. Angew. Chem., Int. Ed. 2012, 51, 2745-2748. doi:10.1002/anie.201108540

26. Kleemann, A.; Engel, J.; Kutscher, B.; Reichert, D. Pharmaceutical Substances, 4th ed.; Georg Thieme Verlag: Stuttgart, 2001.

27. Kamijo, S.; Tao, K.; Takao, G.; Tonoda, H.; Murafuji, T. Org. Lett. 2015, 17, 3326-3329. doi:10.1021/acs.orglett.5b01550

28. Liu, J.; Zhang, X.; Yi, H.; Liu, C.; Liu, R.; Zhang, H.; Zhuo, K.; Lei, A. Angew. Chem., Int. Ed. 2015, 54, 1261-1265. doi:10.1002/anie.201409580

29. Ren, L.; Wang, L.; Lv, Y.; Li, G.; Gao, S. Org. Lett. 2015, 17, 2078-2081. doi:10.1021/acs.orglett.5b00602

30. Itoh, M.; Hirano, K.; Satoh, T.; Miura, M. Org. Lett. 2014, 16, 2050-2053. doi:10.1021/ol500655k

31. Xie, H.; Liao, Y.; Chen, S.; Chen, Y.; Deng, G.-J. Org. Biomol. Chem. 2015, 13, 6944-6948. doi:10.1039/C5OB00915D

32. Huang, Y.; Chen, T.; Li, Q.; Zhou, Y.; Yin, S.-F. Org. Biomol. Chem. 2015, 13, 7289-7293. doi:10.1039/C5OB00685F

33. Sterckx, H.; De Houwer, J.; Mensch, C.; Caretti, I.; Tehrani, K. A.; Herrebout, W. A.; Van Doorslaer, S.; Maes, B. U. W. Chem. Sci. 2016, 7, 346-357. doi:10.1039/C5SC03530A 
34. The $\mathrm{p} K_{\mathrm{a}}$ values mentioned are those of the corresponding monosubstituted pyridines since the benzyl group is the same in every pyridine and data for the compounds are not available. Tables of Rate and Equilibrium Constants of Heterolytic Organic Reactions; Palm, V., Ed.; VINITI: Moscow-Tartu, 1975-1985.

35. Güven, A. Int. J. Mol. Sci. 2005, 6, 257-275. doi:10.3390/i6110257

36. Adam, S. Tetrahedron 1989, 45, 1409-1414. doi:10.1016/0040-4020(89)80138-3

37. World Health Organization (WHO) website. http://www.who.int/medicines/publications/essentialmedicines/en/.

38. Schlagenhauf, P.; Adamcova, M.; Regep, L.; Schaerer, M. T.; Rhein, H.-G. Malar. J. 2010, 9, 357. doi:10.1186/1475-2875-9-357

39. Lutz, R. E.; Ohnmacht, C. J.; Patel, A. R. J. Med. Chem. 1971, 14, 926-928. doi:10.1021/jm00292a008

40. Niwa, T.; Yorimitsu, H.; Oshima, K. Angew. Chem., Int. Ed. 2007, 46, 2643-2645. doi:10.1002/anie.200604472

41. Hems, W. P.; Jackson, W. P.; Nightingale, P.; Bryant, R. Org. Process Res. Dev. 2012, 16, 461-463. doi:10.1021/op200354f

42. Genovino, J.; Lütz, S.; Sames, D.; Touré, B. B. J. Am. Chem. Soc. 2013, 135, 12346-12352. doi:10.1021/ja405471h

43. Class 1 metals include metals that are known or suspect human carcinogens or show any other significant toxicity. Class 2 metals include metals with lower toxicity to man and are typically encountered with administration of medicinal products. Class 3 metals include metals with no significant toxicity and are well tolerated up to doses far exceeding typically encountered with the administration of medicinal products. European medicines agency, committee for medicinal products for human use, see http://www.ema.europa.eu/ema/index.jsp?curl=pages/regulation/gener al/general_content_000356.jsp\&mid=WC0b01ac0580028e8c for a detailed description.

44. Henderson, R. K.; Jiménez-González, C.; Constable, D. J. C.; Alston, S. R.; Inglis, G. G. A.; Fisher, G.; Sherwood, J.; Binks, S. P.; Curzons, A. D. Green Chem. 2011, 13, 854-862. doi:10.1039/c0gc00918k

45. Prat, D.; Wells, A.; Hayler, J.; Sneddon, H.; McElroy, C. R.; Abou-Shehada, S.; Dunn, P. J. Green Chem. 2016, 18, 288-296. doi:10.1039/C5GC01008J

46. Pieber, B.; Kappe, C. O. Green Chem. 2013, 15, 320-324. doi:10.1039/c2gc36896j

\section{License and Terms}

This is an Open Access article under the terms of the Creative Commons Attribution License (http://creativecommons.org/licenses/by/2.0), which permits unrestricted use, distribution, and reproduction in any medium, provided the original work is properly cited.

The license is subject to the Beilstein Journal of Organic Chemistry terms and conditions: (http://www.beilstein-journals.org/bjoc)

The definitive version of this article is the electronic one which can be found at:

doi:10.3762/bjoc. 12.16 